\title{
Moneda, imágine y poder. El ejemplo de los Maravedíes
}

\author{
Coin, imagine and power. The example of the Maravedíes
}

Enviado em: 15/04/2018

Aceito em: 29/07/2018

Cláudio Umpierre Carlan ${ }^{1}$

\section{Resumo:}

O presente trabalho busca discutir a moeda como um objeto que extravasa seus sentidos meramente econômicos ou sociais, buscando valorizar seus componentes materiais e imagéticos. Tais componentes podem fornecer ao pesquisador muitas outras informações tais como geográficas, ideológicas, estéticas, políticas, estatais, jurídicas ou religiosas, de um determinado povo. O caso dos meravedíes, que começaram a ser cunhadas pelo rei de Castela, Alfonso VI (1040 - 1109), mas que exerceram poder simbólico nas Américas séculos depois, ou a apropriação de símbolos monárquicos pela ditadura franquista, são alguns dos exemplos aquí trazidos como forma de mostrar a importância material e simbólica das moedas e a importância dos seus estudos, tanto para a arqueológia, quanto para as ciências patrimoniais e para a história.

Palabras-chave: moeda, imagética, poder simbólico

\begin{abstract}
:
The present work seeks to discuss the currency as an object that goes beyond its merely economic or social senses, seeking to value its material and imagery components. Such elements may provide the researcher with many other information, such as geographic, ideological, aesthetic, political, state, legal or religious, of a particular people. The case of the meravedíes, who began to be minted by the King of Castile, Alfonso VI (1040 - 1109), but who exercised
\end{abstract}

\footnotetext{
1 Doctor en História Cultural (UNICAMP), Investigador Del Grupo Arqueologia Histórica de la UNICAMP, Brasil. Profesor-Associado I de la Universidad Federal de Alfenas, Minas Gerais, Brasil (UNIFAL-MG), y del Programa de Pós Graduación em História Ibérica (PPGHI / UNIFAL-MG).
} 
symbolic power in the Americas centuries later, or the appropriation of monarchist symbols by the Francoist dictatorship, are some of the examples brought here as way of showing the material and symbolic importance of coins and the importance of their studies, both for archeology, as well as for patrimonial sciences and for history.

Keywords: currency, imagery, symbolic power

\section{Introducción}

Las monedas han sido estudiadas por los historiadores bajo el prisma de mercadería, objeto de cambio. Buscó juntarla con la historia social, o sea, con los reflejos que la mutación monetaria produjo en la sociedad a nivel de salarios, costo de vida y los consecuentes comportamientos colectivos ante éstos. El estudioso de la moneda se ha preocupado más con el cuerpo económico social que ella servía que con el metal que producía y la informaba. Estructuralmente éste transponía los límites geográficos del poder que la emitía y definía ideológicamente no sólo un pueblo, pero también la civilización a la que éste pertenecía (CARLAN: 2005, p. 741).

El hombre contemporáneo difícilmente puede unir la moneda a un medio de comunicación entre pueblos distantes. Al poseedor romano de una determinada especie monetaria desconocida, ésta le hablaba por el metal noble o no en que era cuñada, por el tipo de legenda. El primero le informaba la riqueza de un reino y los otros dos elementos le decían algo sobre el arte, o sea, el mayor o menor refinamiento técnico usado en el fabrico del numerario circulante, sobre el poder emisor y, sobretodo, sobre la ideología político-religiosa que le daba el cuerpo. Es dentro de este último aspecto que pretendemos explorar la fuente numismática.

Los símbolos que habitan la numismática están dotados siempre de una clara organización hieroglífica, pues proceden del hecho de que esas imagines difundidas se articulan siempre con el idioma figurado, en lo cual el poder se expresa secularmente.

Revista Memória em Rede, Pelotas, v.10, n.19, Jul./Dez.2018 - ISSN- 2177-4129 
Donis Dondis afirma que, para los analfabetos, el lenguaje hablado, la imagen y el símbolo continúan siendo los principales medios de comunicación. Y entre ellos solo el visual puede ser mantenido en cualquier circunstancia práctica.

\footnotetext{
“...eso es tan verdadero como ha sido a lo largo de la historia. En la Edad Media y en el Renacimiento, el artista servía a la Iglesia como propagandista...El comunicador visual ha servido al imperador y al comisario del pueblo...la comunicación pictórica dirigida a los grupos de bajo índice de alfabetización se pretende ser eficaz, debe ser simple y realista..." (DONDIS, 1997, p.184)
}

Esas representaciones son comúnmente alegóricas o simbólicas y el mensaje que transmiten va, casi siempre, más allá de los rasgos visibles. Se encuentran con frecuencia, en esas monedas, nombres de ciudades, países, festivales, monumentos famosos, divinidades, miembros de una familia, que auxilian en la interpretación de su significado y sentido.

Se trata de una exposición de ideas, una composición de emblemas, como el birrete frigio que tiene el significado de libertad, la cornucopia que remete a la abundancia, y la concordia representa la unión de los esfuerzos. En algunos casos también son representadas por manos estrechadas. Otras coberturas, como el velo, que puede indicar modestia o viudez, birretes y yelmos, indicando campañas militares, la ornamentación con la corona de laureles (laureadas), que tienden a asimilar aquellos que las llevan a la divinidad, también son comunes en las representaciones monetarias.

Debemos dejar claro que cualquier sistema de símbolos es una invención o refinamiento de lo que fueron, en otros tiempos, percepciones del objeto dentro de una mentalidad despojada de imagines, tornando el lenguaje visual universal. Dondis aún añade que:

\footnotetext{
"En cuanto medio de comunicación visual impregnado de información de significado universal, el símbolo no existe apenas en el lenguaje. Su uso es mucho más amplio. El símbolo debe ser simple y referirse a un grupo, idea, actividad comercial, institución o partido político..." (DONDIS, 1997, p.93)
} 
La impresión iconográfica de las monedas, dejándose de lado las inscripciones, revela figuras diversas: animales, vegetales, blasones, objetos edificios y emblemas más o menos estilizados. Generalmente, estas figuras se refieren al local de acuñación y a la respectiva autoridad, designada de un modo claro para sus contemporáneos por una figura, una actitud, o atributos cuyos significados hoy muchas veces nos escapan.

Esas representaciones son comúnmente alegóricas o simbólicas y el mensaje que transmiten va, casi siempre, más allá de los rasgos visibles. Se encuentran con frecuencia, en esas monedas, nombres de ciudades, países, festivales, monumentos famosos, divinidades, miembros de una familia, que auxilian en la interpretación de su significado y sentido.

En materia de tipología monetaria, son consideradas como retratos todas las imagines que pretenden representar a sus líderes o "humanos concretos", en su calidad de personas individuales, quiere asuman aspectos realistas, quiere, por el contrario, correspondan a las interpretaciones idealizadas o casi simbólicas. Aún así, se trata de algo bien diferente de la Edad Media, cuando, sacado pocas excepciones, no existían preocupaciones evidentes de semejanza con las individualidades representadas.

La moneda, como documento, puede informar sobre los más variados aspectos de una sociedad. Tanto político y estatal, como jurídico, religioso, mitológico, estético.

\footnotetext{
"Sin duda alguna es el terreno de las ideas políticas y la propaganda donde es más fecundo el servicio de la Numismática a la Historia... [Debemos] reflejar sobre la significación de la moneda en el mundo antiguo, en un mundo donde no existían medios de información comparables a los nuestros, donde el analfabetismo se extendía a numerosas camadas de la población. La moneda es un objeto palpable, objeto que abre todas las puertas y proporciona bien estar. En ella se puede contemplar a la efigie del soberano, mientras los reversos muestran sus virtudes y la prosperidad de la época: Felicitas Temporum, Restitutio Orbis, Victoria e Pax Augusta...son slogans, propaganda." (ROLDÁN-HERVÁS, 1975, p.166)
}

El grande problema de las monedas de bronce es su estado de conservación. En Brasil, en especial en Río de Janeiro, la humedad es una enemiga constante. El clima es enemigo del estado del metal. 
Tampoco podemos ignora los efectos que la naturaleza y el ambiente ejercen sobre el patrimonio, una de las reglas más importantes en materia de conservación. Por ejemplo, los efectos de luz solar, que forma parte de una de la más clásicas leyes de la arquitectura moderna, se encuentra presente en la Carta de Atenas (CURY, 2000, p.88).

Trabajos realizados en Francia por la doctora en Química Maria Filomena Guerra ayudan en la organización de las piezas y sus fechas de fabrico. Los estudios con las ligas metálicas y las cecas son importantes para arqueólogos e historiadores. El oro y la plata españoles son muy diferentes del oro portugués, por ejemplo. La composición química del oro portugués es muy parecida con el oro brasileño. Mientras que en norte de la África es la misma composición del España.

\section{Los Maravedíes: simbología y poder en la Conquista de América}

Los primeros maravedíes fueran cuñados por el rey de Castilla Alfonso VI (1040 1109), después de la conquista de Toledo. En un primer momento las cecas de Toledo las monedas eran de bronce con los símbolos reales da dinastía Jimena o Casa de Navarra (SEAR, 1988, p.61). Pero, origen etimológica es una influenza árabe (amorávides), morabhitis, significa devotos a Dios.

Alfonso VIII (1155 - 1214), da casa de Borgoña, empezó labrar en oro los maravedíes. Todavía fue con Fernando II de León que las monedas llegaran el peso de 3,8 gramos.

Hoy en día hay una discusión en sobre el origen de la palabra maravedí. Algunos autores defienden influencias moras, donde maravedí significa moneda en almorávide. Podríamos llamar de moneda bilingüe usada en los dominios cristianos y moros, legitimando una relación comercial y diplomática con los musulmanes en el reino de Castilla.

Durante el reino de Alfonso X, el sabio (1221 - 1284), ocurrió una grave crisis financiera, obligando el monarca abolir las acuñaciones en oro, cambiando por la plata. 
En siglo XIV los maravedíes fueran utilizados como monedas de cuenta, para las conversiones con las diversas monedas que circulaban por la península ibérica.

Bajo en reinado de los Reyes Católicos, Fernando de Aragón y Isabel de Castillas una serie de monedas fueran cuñadas para circular en América. En la película de Ridley Scout 1492: La conquista del paraíso, el personaje de Cristóbal Colon (Gerard Depardieu) hace una promesa de 100 maravedíes para la primera persona que mirar tierra firme. Asi, podremos imaginar un poco de su importancia.

La Dinastía Trastámara empezó una tipología ceremonial única en España. Fue en primer intento de establecer una frontera clara entre ceremonias de propaganda y ceremonias de legitimación. Hubo ceremonias cuyo objetivo esencial fue producir un efecto propagandístico (NIETO SORIA, 1993, p.23). Los Reyes Católicos acuñaran grandes piezas que se erigen en exponentes de la fuerza política y económica que la corona de Castilla comenzaba a adquirir en Europa. Algunos de eses ejemplares no tendrían la función de circular como monedas y si servir de piezas de representación.

Eran objetos de ostentación que se regalaban en ocasiones solemnes como visitas reales, matrimonios o ofrendas a iglesias y después se guardaban en los tesoros, piezas que su valor material unían un carácter de símbolo de Estado (ALFARO ASINS, 2003, p.102), en Europa o en América, de una manera general.

Como las piezas acuñadas en la Ceca de Sevilla, con bustos afrontados de los Reyes, con la letra S, altura del pecho, rodeada por cuatro puntos (marca de la ceca), en el anverso. En el reverso uno escudo coronado (símbolo de la protección), con las armas de Castilla y León, Aragón, Sicília y Granada (después de la conquista en 1492), cobijado por el águila de San Juan (no confundir con el Águila Imperial, presente en los blasones de los Austrias Españoles). Se trata, según de la Flor, del surgimiento de representaciones de águilas, leones, como también de torres, cruces (DE LA FLOR, 1994, p.183), de la fénix, de imperadores o de personajes pertenecientes a una elite políticoeconómica, que representan la órbita de acción del poder, llegando al punto en que la numismática puede ser definida"como un monumento oficial al servicio del Estado." Acordamos aunque, como afirma Cassirer, “...en lugar de definir el hombre como un 
animal rationale, deberíamos definirlo como un animal symbolicum." (CASSIRER: 1977, p.70).

En los modelos oficiales, durante la dictadura franquista, se incluyó como soporte del Escudo del España el águila de San Juan. El pasado volviendo para legitimar el presente.

Figura 1

Portada de la ceca de Sevilla, España, cerca de la Catedral y lo antiguo barrio judío. De todos los lugares, el más idóneo parecía ser Sevilla. Donde llegaban los metales procedentes de América. Además, era una gran cuidad en la que se concentraba la mayor parte de la actividad comercial del reino. Principal sitio de acuñaciones de las monedas que circulaban en América. Hoy un bar muy tradicional en la noche sevillana.

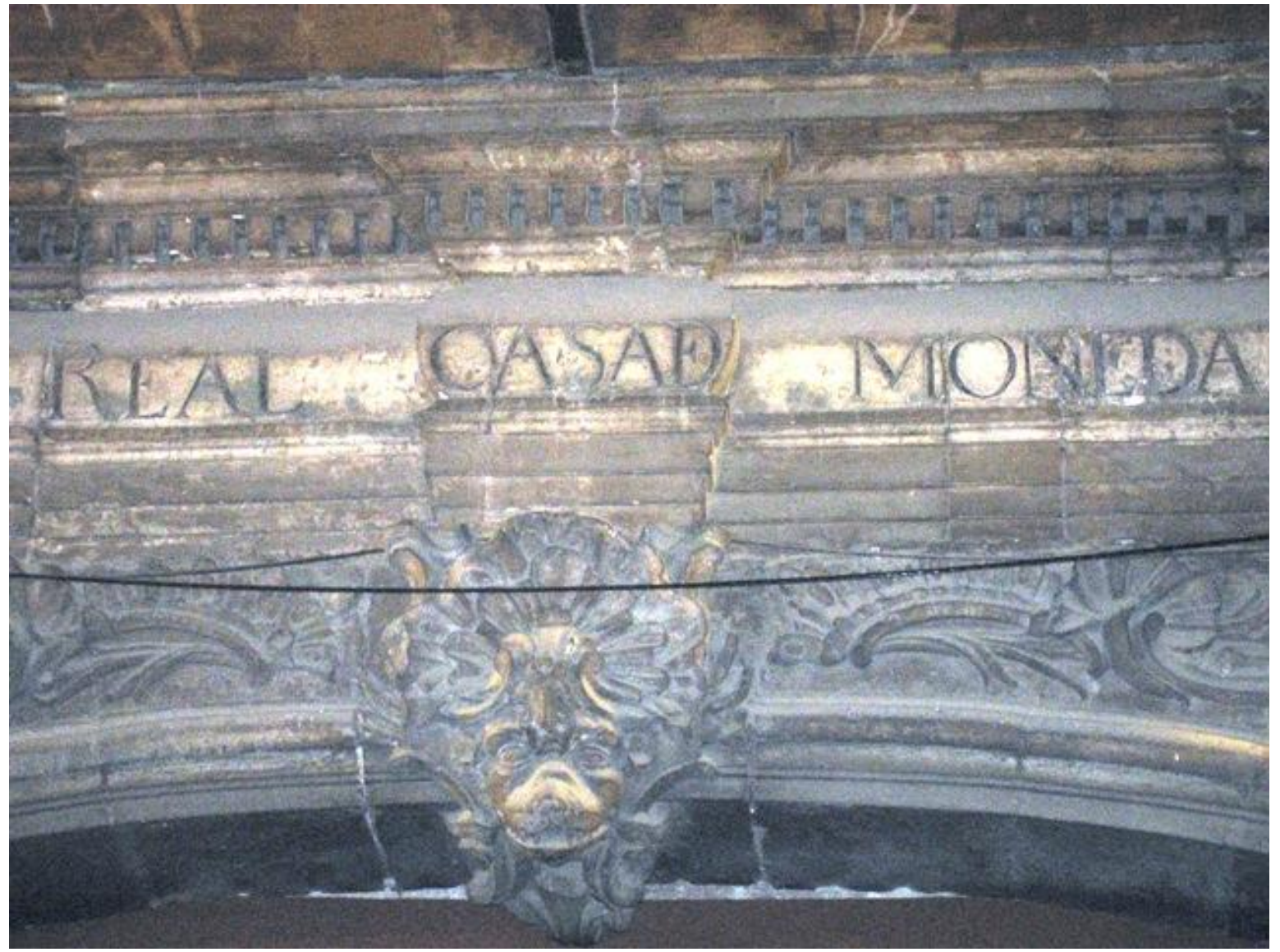

Foto: Cláudio Umpierre Carlan, junho de 2007.

Revista Memória em Rede, Pelotas, v.10, n.19, Jul./Dez.2018 - ISSN- 2177-4129 
Segundo Nieto Soria es una ceremonia de acceso al poder. Celebraciones mediante las cuales se simbolice alguna forma de pacto entre la pareja imperial. Una representación del reino y de la unificación del Estado. El reconocimiento por esa representación de los derechos o de las pretensiones al trono de la Dinastía Trastámara, ahora unida por las bodas con la Dinastía de Aragón. Asegurándose así legitimidad política para esos derechos o pretensiones.

Francisco Franco (1892 - 1975), en 1966, he utilizado una política propagandista muy semejante a política de los Reyes Católicos. He empezado el fabrico de una serie de monedas conmemorativas de plata (100 pesetas). En su anverso la leyenda Francisco Franco Caudillo de España por la G. de Dios. Es una invocación al divino, segundo el dictador, su gobierno era por la voluntad de Dios y no de los hombres. Lo mismo discursos de los reyes mesopotámicos. En el reverso los antiguos reinos españoles (hoy las comunidades autónomas) estaban representados. La legitimación divina y la "segunda unificación" española bajo las manos de ferro de la dictadura fascista. 
Figura 2

Prensa de acuñaciones de monedas de la Ceca de Sevilla (fecha de 1735). Lo original se queda en al Alcázar, Segovia, España. Alrededor de 1550 loa alemanes inventaron máquinas para acuñar moneda. El artilugio consistía en un ingenio o molino laminador que se movía a través de una rueda hidráulica. Las monedas salían impresas por ambos lados en la tira de metal y después se cortaban quedando perfectamente redondas. No se podía más recortarlas para robarles trocitos de oro ou plata.

Sin embargo, reino español enviaba dinero a América en monedas acuñadas a martillo. Despues de 1681, ninguna ceca puede trabajar con martillos.
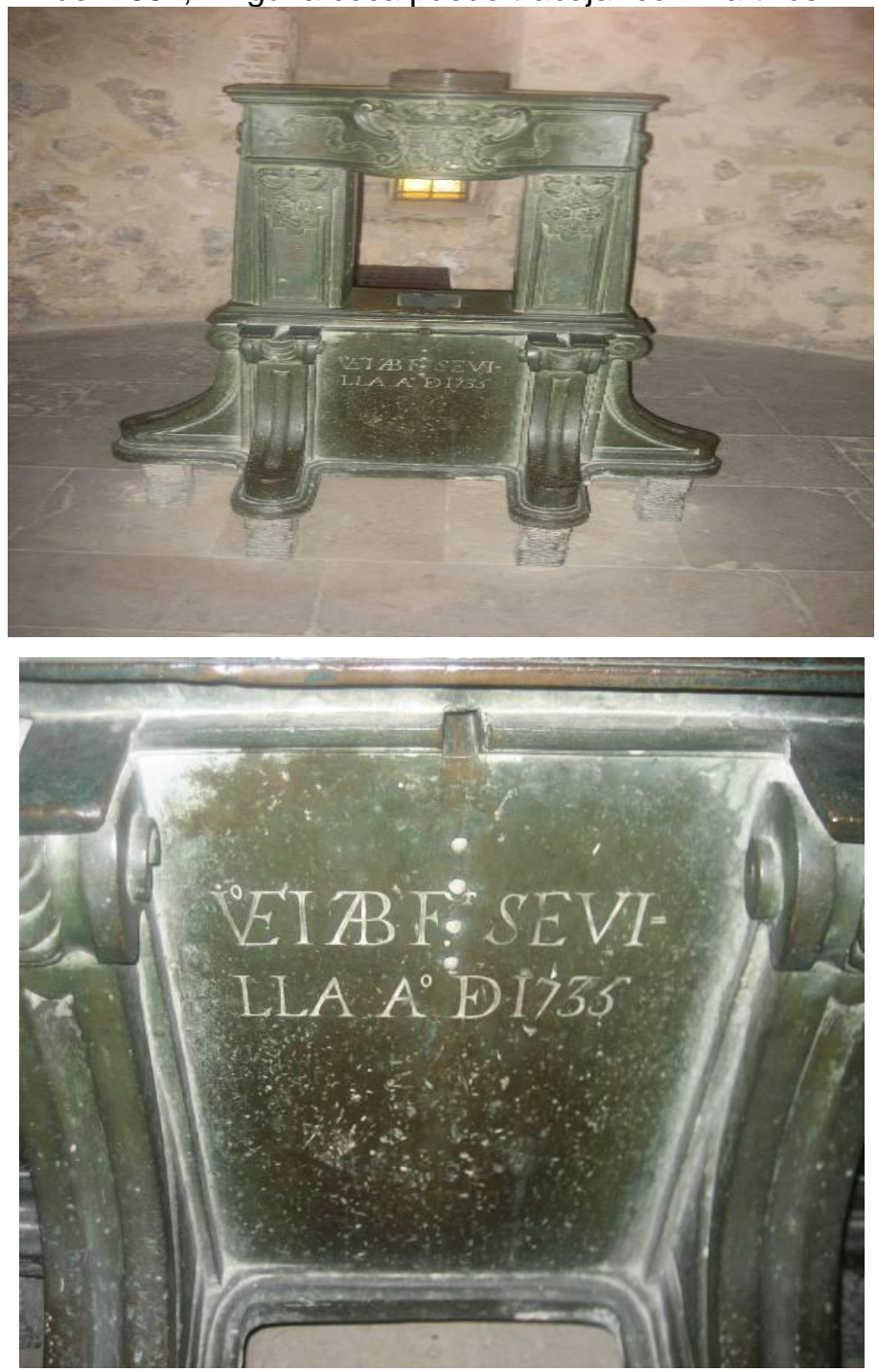

Foto: Cláudio Umpierre Carlan, Octubre de 2009. 


\section{Consideraciones Finales}

De manera general, puede decirse que la historia no ha sido escrita únicamente a través de los museos, sino que es el reflejo de la evolución urbana y especialmente de su gente. Calles, edificios, plazas, fuentes, y todos los espacios cuentan con una singular tradición, marcan el ir y venir de nuestra civilización.

La definición de patrimonio se ha ido ampliando. No sólo los sitios arqueológicos, como Ouro Preto y Mariana (barroco brasileño) constituyen acervos arqueológicos sino que también expanden su importancia hacia bienes muebles, como es el caso de las monedas.

Adquirir el conocimiento del pasado, cosa que ocurre a través de la investigación histórica, es al margen de las propiedades que se le puedan atribuir, parte del proceso cognoscitivo humano (TOPOSLKY, 1985, p.239).

El siglo XV - XVI representó una época caracterizada por la extraordinaria ampliación de actividad ceremonial de significación política en torno a la realeza. Una necesidad de legitimación y de propaganda política, principalmente después de 1492.

Este sistema tuvo efectos de orden, legitimación y propaganda, siendo su objetivo principal ofrecer una imagen global o parcial del poder regio que contribuyera (NIETO SORIA, 1993, p.162), a mostrar la superioridad incomparable de este poder, provocar una reacción de adhesión o, simplemente, hacerlo más aceptable.

En la moneda podremos mirar una dimensión pública o popular, en la que existe un cierto predominio de lo teatral, siendo el objetivo principal la exhibición de la persona regia; mientras que, por otro lado, tiene lugar lo que podríamos calificar como el acto de legitimación estamental (NIETO SORIA, 1993, p.32). 
Agradecimientos:

Amiga y maestra profesora Lourdes Domínguez por la oportunidad de cambiarmos de ideas; a Pedro Paulo Abreu Funari, Jose Remsal - Rodríguez, Rita Juliana Poloni.

\section{Referencia}

ALFARO ASINS, Carmen. EI Departamento de Numismática Del Museo Arqueológico Nacional. Madrid: Ministério de Educácion, Cultura y Deporte, 2003.

CARLAN, Cláudio Umpierre. Las Monedas de Constancio II en el Acervo del Museo Histórico Nacional del Río de Janeiro: características. In: ALFARO, Carmen, MARCOS, Carmen y OTERO, Paloma. Actas del XIII Congreso Internacional de Numismática. Madrid: Museo Arqueológico Nacional, 2005.

CARLAN, Cláudio Umpierre. FUNARI, Pedro Paulo Abreu. Moedas: a numismática e o estudo da História. São Paulo: Annablume, 2012.

CASSIRER, E. Antropologia Filosófica. Ensaio sobre o Homem. São Paulo: Mestre Jou, 1977.

CURY, Isabelle. Cartas Patrimoniais. Segunda Edição. Rio de Janeiro: Edições do Patrimônio, 2000.

DOMíNGUEZ, Lourdes. Temas Arqueológicos de Cuba y el Caribe. Campinas: Caluh, 2014.

DONDIS, Donis. Sintaxe da Linguagem Visual. Tradução de Jefferson Luis Camargo. $2^{a}$ ed. São Paulo: Martins Fontes, 1997. 
FUNARI, Pedro Paulo Abreu. ORSE JR., Charles E. SCHIAVETTO, Solange Nunes de Oliveira. Identidades, discurso e poder: Estudos da arqueologia contemporânea. São Paulo: Annablume / FAPESP, 2005.

FUNARI, Pedro Paulo Abreu e CARLAN, Cláudio. Arqueologia Clássica e Numismática. Coleção Textos Didáticos n. 62. Campinas: IFCH / UNICAMP, 2007.

FLOR, Fernando de la. Emblemas Lecturas de la Imagen Simbólica. Madrid: Aliança Editorial, 1995.

GUERRA, Maria Filomena. GONDONNEAU, Alexandra. As Tecnologias de Fabrico das Ligas Amoedáveis e a Proveniência dos Metais Utilizados: Perspectivas Abertas pelas Novas Técnicas de Análise Elementar. Lisboa: Separata das Actas do IV Congresso Nacional de Numismática, 1998.

GUINOT RODRÍGUEZ, Enric. La Baja Edad Media en los siglos XIV y XV. Economia y Sociedad. Madrid: Síntesis, 1999.

JUNGE, Ewald. The Seaby Coin Encyclopaedia. Second impression with revisions. London: British Library, 1994.

MACKAY, Angus. Money, prices and politics in Fitfteenth Century Castile. London: Royal Historical Society, 1981.

MOREIRA, Ronaldo Auad. CARLAN, Cláudio Umpierre. FUNARI, Pedro Paulo. Iconografia e Semiótica: uma abordagem histórica. São Paulo: Annablume, 2015.

NIETO SORIA, Jose Manuel. Ceremonias de la Realeza. Propaganda y legitimación en la Castilla Trastámara. Madrid: Editorial Nerea, 1993.

NIETO SORIA, Jose Manuel. Fundamentos ideológicos Del Poder Real en Castilla (siglos XIII - XVI). Madrid: EUDEMA S. A., 1988.

ROLDÁN HERVÁS, J. M. Introducción a la Historia Antigua. Madrid: Ediciones Istmo, 1975, p. 166.

TOPOLSKY, Jerzy. Metodologia de la História. Traducción de María Luisa Rodríguez Tapia. 2a. ed. Madri: Cátedra, 1985. 